\title{
Correction to: A Novel Dop2/Invertebrate-Type Dopamine Signaling System Potentially Mediates Stress, Female Reproduction, and Early Development in the Pacific Oyster (Crassostrea gigas)
}

\author{
Julie Schwartz ${ }^{1}$ (D) Emilie Réalis-Doyelle ${ }^{1} \cdot$ Lorane Le Franc $^{1} \cdot$ Pascal Favrel $^{1}$
}

Published online: 9 October 2021

๑) Springer Science+Business Media, LLC, part of Springer Nature 2021

\section{Correction to: Marine Biotechnology https://doi.org/10.1007/s10126-021-10052-5}

The original version of this article unfortunately contained a mistake in the Supplementary Information section. The captured ESM file is inadvertently not updated. The correct version is included herewith.

The original article has been corrected.
The original article can be found online at https://doi.org/10.1007/ s10126-021-10052-5.

Julie Schwartz

julie.schwartz@unicaen.fr

1 UMR BOREA, Normandie Université, UNICAEN, Sorbonne Universités, IRD 207, Esplanade de la Paix, CNRS-806714032 CAEN cedex 5, MNHN, France
Supplementary Information The online version contains supplementary material available at https://doi.org/10.1007/s10126-021-10070-3.

Publisher's Note Springer Nature remains neutral with regard to jurisdictional claims in published maps and institutional affiliations. 